\title{
Preparation and evaluation of erucamidopropyl dimethyl amine oxide used as alkali-free oil displacement agent
}

\author{
Changxin Shi $^{1} \cdot$ Shemin Song $^{1} \cdot$ Fajun Guo ${ }^{1} \cdot$ Hongmei Ren ${ }^{1} \cdot$ Hong Zhang ${ }^{1} \cdot$ \\ Zhongyu Fan ${ }^{1}$
}

Received: 21 October 2016/ Accepted: 26 February 2017/Published online: 10 March 2017

(C) The Author(s) 2017. This article is published with open access at Springerlink.com

\begin{abstract}
Surfactant is a kind of chemical that is widely used in the oilfield. It often serves as chemical oil displacement agents in the surfactant-polymer flooding or alkali-surfactant-polymer flooding. The commonly used surfactant is petroleum sulfonate. However, its unstable property often limits its use. In this paper, erucamidopropyl dimethyl amine oxide was prepared and its potential use in surfactant-polymer flooding was investigated. The results showed that the interfacial tension between crude oil and surfactant-polymer solution could be lowered to ultralow at a concentration of $0.05 \%(\mathrm{~m} / \mathrm{m})$ surfactant. The surfactant-polymer system $(0.05 \%$ of surfactant and $1500 \mathrm{mg} / \mathrm{L}$ of polymer) could withstand adsorption twice. The core flood test indicated the above system could give $22.5 \%$ of incremental oil recovery over water flood.
\end{abstract}

Keywords Synthesis · Amine oxide $\cdot$ Alkali-free flooding

\section{Introduction}

Some tertiary recovery technologies have been tested to improve oil recovery. Among them, surfactant-polymer flooding is one of the promising methods (Samanta et al. 2011a). The commonly used polymer is partially hydrolyzed polyacrylamide, whereas surfactants are different. Until now, many types of surfactants, such as petroleum sulfonates (Zhu 2007), internal olefin sulfonates (Sanz and Pope 1995), sulfobetaine ( $\mathrm{Li}$ et al. 2012), ether sulfonate

Changxin Shi

cxshi@qq.com

1 Exploration and Development Research Institute of Huabei Oilfield Company, Renqiu 062552, Hebei, China
(Carmona et al. 1985), propoxylated sulfate (Witthayapanyanon and Acosta 2006), methylnaphthalene sulfonate (Zhao et al. 2006), and natural surfactant (Samanta et al. 2011b), have been developed for improving oil recovery. However, some of these surfactants and their synthetic routes are relatively complicated, or their interfacial activity cannot meet the needs if not mix with other surfactants.

Amine oxide is a type of zwitterionic surfactant. It is $\mathrm{pH}$-sensitive. In acidic solution, it is protonated and becomes a cationic surfactant, while in neutral or alkaline condition, it becomes a nonionic surfactant (Li 2011). It has been wildly used in shampoos, detergents, and cosmetics due to its low toxicity (Lu 1996). It shows excellent salt tolerance ability and thermal stability (Wang et al. 2011; Olsen 1989) and can produce low interfacial tension and develop viscosity without addition of polymer, which is important for oil recovery.

Generally speaking, when used as an oil displacement agent, according to capillary number theory, the interfacial tension between the crude oil and surfactant solution has to reach ultralow $(<10-2 \mathrm{mN} / \mathrm{m})$ levels. To achieve ultralow interfacial tension, it often requires that the surfactant has enough hydrophobicity. However, the chain length of the conventional surfactant is less than 18 (Kong 2009). To overcome the chain length limitations, many synthetic routes were developed (Cui et al. 2011; Qiao et al. 2012). Erucic acid, an unsaturated fatty acid with a C22 hydrophobic chain, is an ideal material to synthesize the oil displacement agent. Moreover, it can be obtained from the rapeseed oil processing by-products (Chu and Feng 2013).

In this work, erucamidopropyl dimethyl amine oxide was prepared by using erucamidopropyl dimethyl amine and hydrogen peroxide, and then used for oil recovery in the absence of alkali. 


\section{Experimental section}

\section{Materials}

Erucamidopropyl dimethyl amine (purity $>98 \%$ ) was provided by Solvay (Zhang Jia Gang) Fine Chemical Co. Ltd. Hydrogen peroxide (30\%) was purchased from Aladdin Reagent Company. Ethylenediaminetetraacetic acid disodium salt, petroleum ether, acetone, and sodium sulfite of AR grade were purchased from Tianjin Damao Reagent Company. Crude oil was derived from the Jing 11 block of Huabei oil field. The density of oil is $810 \mathrm{~kg} / \mathrm{m}^{3}$. The water used in the experiment is simulated formation water containing $10,954 \mathrm{mg} / \mathrm{L}$ of total dissolved solids. Partially hydrolyzed polyacrylamide (HPAM) with a $30 \%$ degree of hydrolysis was provided by Hengju Company. Its molecular weight is $28 \%$.

\section{Methods}

The FT-IR spectra were recorded on a spectrometer using the $\mathrm{KBr}$ pellets technique.

Mass spectrometry was performed with a Waters Xevo G2 QTof mass spectrometer. The operational parameters were listed as flows: capillary voltage: $3 \mathrm{kV}$; the desolvation temperature: $500{ }^{\circ} \mathrm{C}$; the desolvation temperature rate: $1000 \mathrm{~L} / \mathrm{h}$; cone gas flow: $50 \mathrm{~L} / \mathrm{h}$; source temperature: $150{ }^{\circ} \mathrm{C}$; collision gas: argon.

The interfacial tensions were measured at $54{ }^{\circ} \mathrm{C}$ using a TX 550 spinning drop interfacial tensiometer at the rotational speed of $5000 \mathrm{rpm}$.

Core flood experiments were carried out on sand-filled columns. The column was $0.305 \mathrm{~m}$ long and $0.152 \mathrm{~m}$ in diameter. The displacement procedure was implemented according to the methods of Shi (Shi et al. 2014): The core was first saturated with Jing 11 crude oil and aged $24 \mathrm{~h}$. The core was then flooded with water at the rate of $0.6 \mathrm{ml} / \mathrm{min}$ until the water cut reached $98 \%$. After that, 0.3 pore volume of chemical agent slug was injected into the core and flooded with water until water cut was $98 \%$. The concentration of polymer used in the experiment was $1500 \mathrm{mg} / \mathrm{L}$.

The absorption experiments were carried out using 70-90-mesh natural quartz sand. The surfactant-polymer solution and the sand mixture were first transferred into a conical flask with stopper and then placed in a shaking table $(180 \mathrm{rpm})$ under $54{ }^{\circ} \mathrm{C}$ for $24 \mathrm{~h}$.

\section{Synthesis}

$1 \mathrm{~g}$ of ethylenediaminetetraacetic acid disodium salt was first dissolved in $50 \mathrm{ml}$ distilled water and then poured into a 250-ml three-neck flask. Next, $8.5 \mathrm{~g}$ of erucylamide dimethyl amine was dissolved in $50 \mathrm{ml}$ acetone and then poured into the flask. The flask was equipped with a magnetic stir bar, a reflux condenser, and placed in water bath at $40{ }^{\circ} \mathrm{C}$. The mixture was stirred vigorously, and $4.55 \mathrm{~g}$ of hydrogen peroxide was then added drop by drop. Afterward, the temperature was raised to $70^{\circ} \mathrm{C}$. The reaction was carried out at this temperature for $12 \mathrm{~h}$. After the reaction was complete, $3 \mathrm{~g}$ of sodium sulfite was added to remove the excess hydrogen peroxide and the acetone was removed by rotary evaporation. The mixtures then were dried using a vacuum oven method. The obtained solid was first washed with petroleum ether, followed by ethanol washing and vacuum drying.

\section{Results and discussion}

\section{Structure confirmation}

\section{Infrared spectroscopy}

The IR spectrum of the product is presented in Fig. 1. The band at $3321 \mathrm{~cm}^{-1}$ is assigned to the stretching vibrations of $\mathrm{N}-\mathrm{H}$ bond. The band at 3005 can be assigned to the stretching vibration of $\mathrm{C}=\mathrm{C}$. The strong absorptions at 2921 and $2852 \mathrm{~cm}^{-1}$ correspond to the asymmetric and symmetric stretching vibration of $\mathrm{CH}_{2}$, respectively. The peak at $1646 \mathrm{~cm}^{-1}$ refers to the stretching vibration of $\mathrm{C}=\mathrm{O}$. The peak at $1551 \mathrm{~cm}^{-1}$ is due to the bending vibration of the $\mathrm{C}=\mathrm{O}$. The band at $1466 \mathrm{~cm}^{-1}$ is due to the stretching vibration of $\mathrm{C}=\mathrm{C}$. The band at $1378 \mathrm{~cm}^{-1}$ is due to the bending vibration of $\mathrm{CH}_{3}$. The band at $929.5 \mathrm{~cm}^{-1}$ is the characteristic absorption peak of the $\mathrm{N}-\mathrm{O}$.

\section{Mass spectrometry}

The mass spectrum of the product is shown in Fig. 2.

The ion peak at $\mathrm{m} / \mathrm{z}=439.4$ corresponds to $[\mathrm{M}+1]^{+}$, while the ion peaks at $\mathrm{m} / \mathrm{z}=440.4,441.4$ and 877.8 correspond to $[\mathrm{M}+2]^{+},[\mathrm{M}+3]^{+},[2 \mathrm{M}]^{+}$, respectively.

\section{Interfacial tension measurements}

The dynamic interfacial tension between the crude oil and surfactant solution is shown in Fig. 3.

It could be seen from Fig. 3 that the interfacial tension between the oil and water could be lowered to ultralow levels at first and then increased to the magnitude of $10^{-2}$. This is because the oil droplet was first elongated and then broken up into several smaller droplets. The retraction of the droplet caused the interfacial tension increase. 
Fig. 1 FT-IR spectrum of erucamidopropyl dimethyl amine oxide

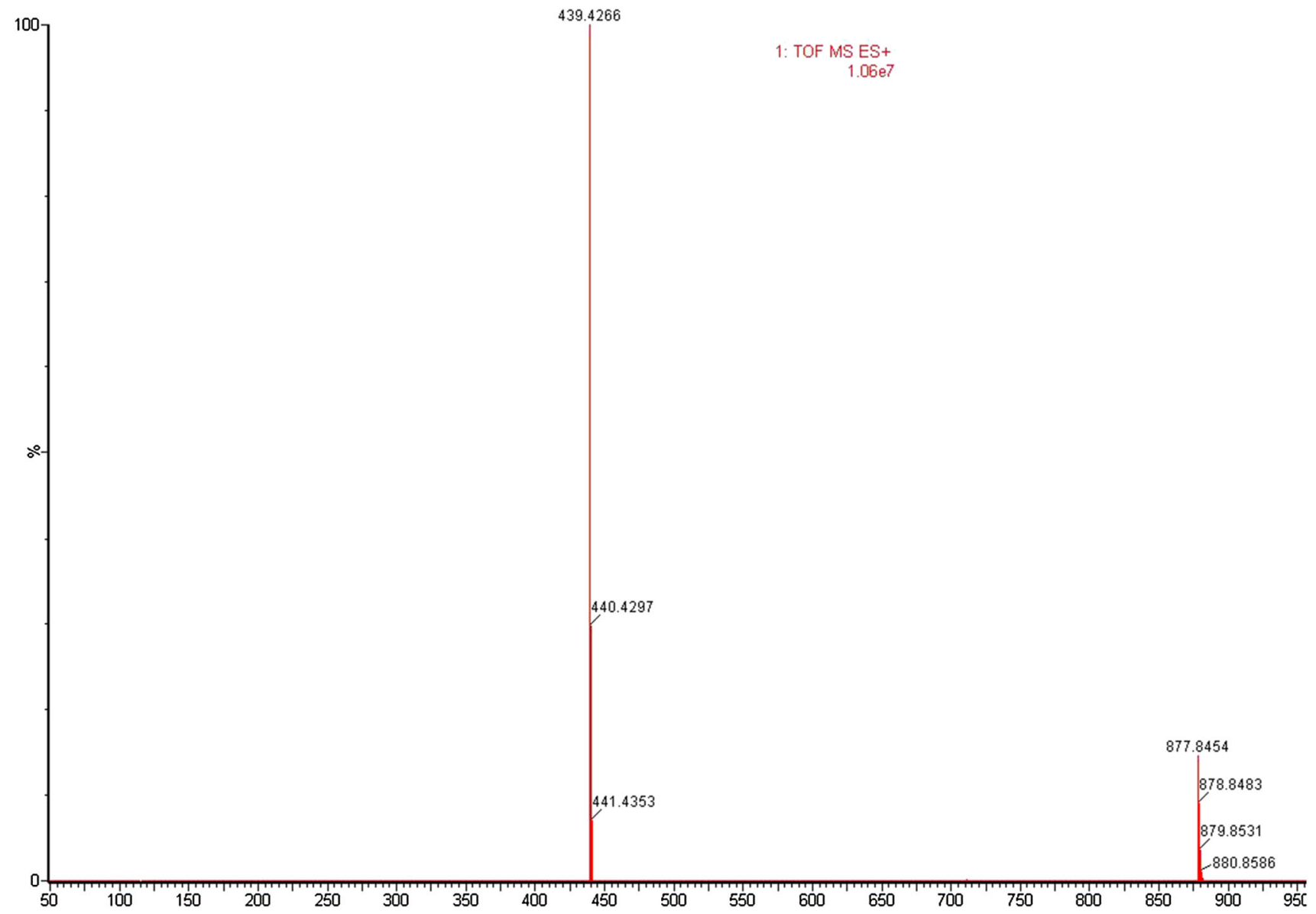

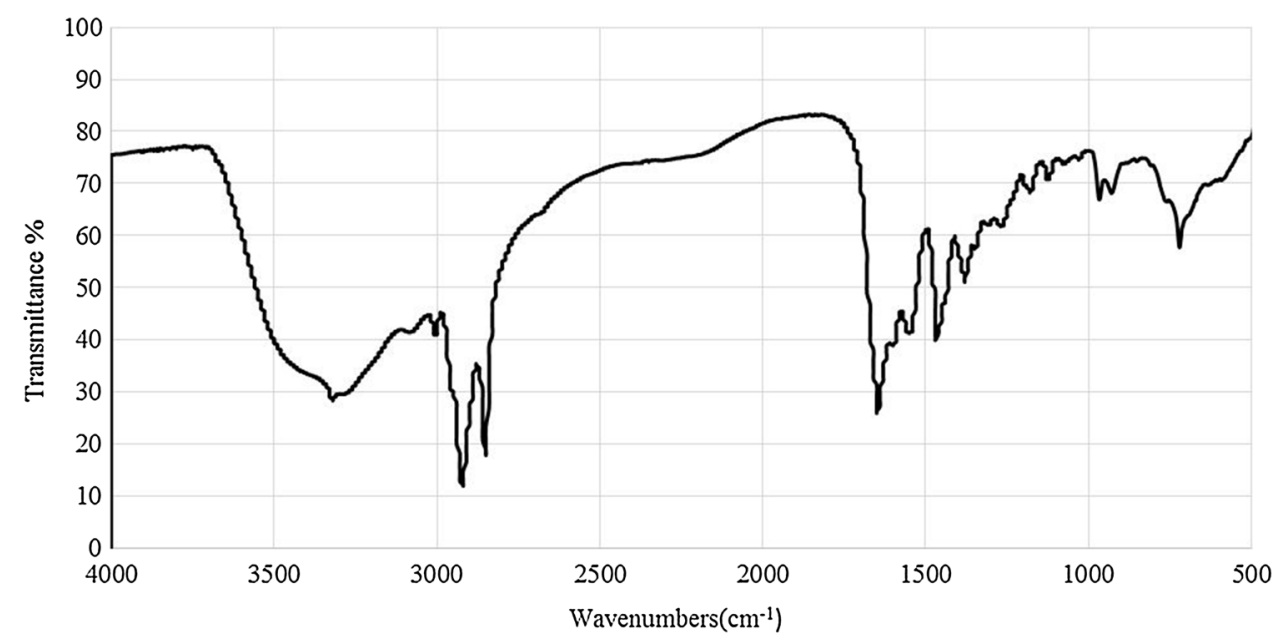

00

Fig. 2 Mass spectra of erucamidopropyl dimethyl amine oxide

While in surfactant-polymer flooding, the addition of the polymer often has an effect on the interfacial tension. The effects of polymer on the interfacial tension are given in Fig. 4. The polymer was above-mentioned HPAM. Its concentration, which is commonly used in the experiments, was $1500 \mathrm{mg} / \mathrm{L}$. 
Fig. 3 Dynamic interfacial tension between crude oil and surfactant solutions
Fig. 4 Dynamic interfacial tension between crude oil and surfactant-polymer solutions
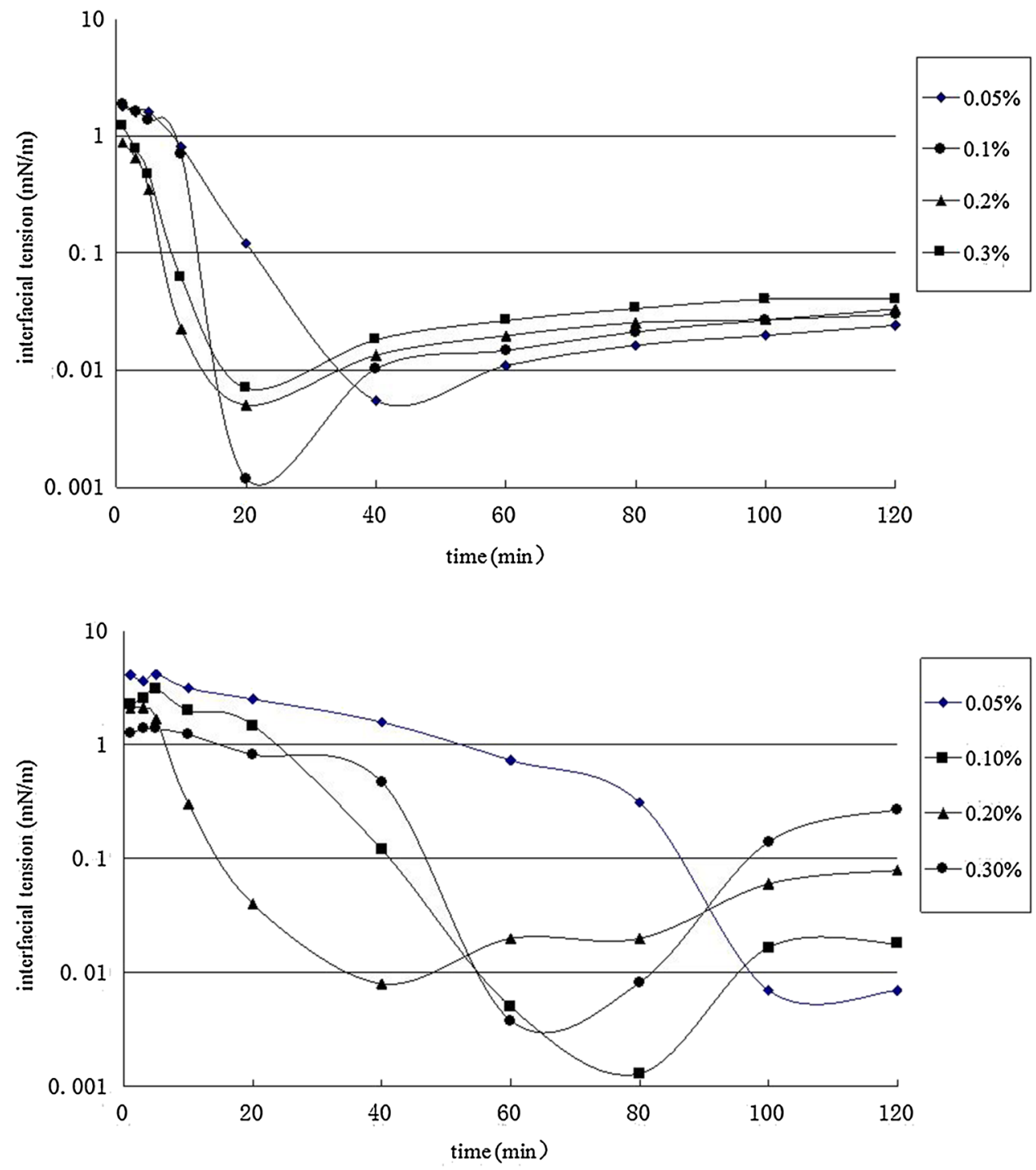

transient and equilibrium interfacial tension. Some scholars argued that the higher oil recovery could be obtained only if the transient interfacial tension value is lower than $0.01 \mathrm{mN} / \mathrm{m}$ ( $\mathrm{Li}$ and Chen. 2006). While others believed that the ultralow equilibrium interfacial tension value is a necessity for higher oil recovery (Zhu and Yang 1994). From Fig. 4, we could also see that in the presence of polymer, it took a longer time to reach the lowest interfacial tension values. This is because the formation of lowest interfacial tension is connected with absorption and desorption of the surfactant at the oilwater interface. If the absorption rate is higher than that of desorption, the surfactant will accumulate at the interface, which will lead to the interface tension decrease. The addition of polymer increased the viscosity of the solution; thus, the surfactant transfer rate was slowed. As a result, more time is needed to reach the maximum accumulated absorption quantity (Chen et al. 2001).

\section{Absorption experiments on quartz sand}

After the surfactant-polymer system was injected into the targeted reservoir, the adsorption of the system on the reservoir rocks would have an influence on the interfacial tension. Some mixed surfactant flooding formulations showed a good interfacial activity (Cui et al. 2012; Li et al. 2010); however, chromatographic separation might occur in practical application due to the adsorption. Obviously, the single surfactant formulation could effectively avoid the chromatographic separation. To investigate the effect of the adsorption on the interfacial tension of the synthetic oxide surfactant formulation, absorption experiments were carried out. The effect of adsorption times on the interfacial tension was displayed in Fig. 5. The surfactant concentration used in the experiment was $0.05 \%$. This is because the ultralow equilibrium interfacial tension was reached at this concentration. As shown in Fig. 5, the interfacial tension of surfactant-polymer was increased to $10^{-1} \mathrm{mN} / \mathrm{m}$ after thrice absorption. 
Fig. 5 Effects of absorption on interfacial tension

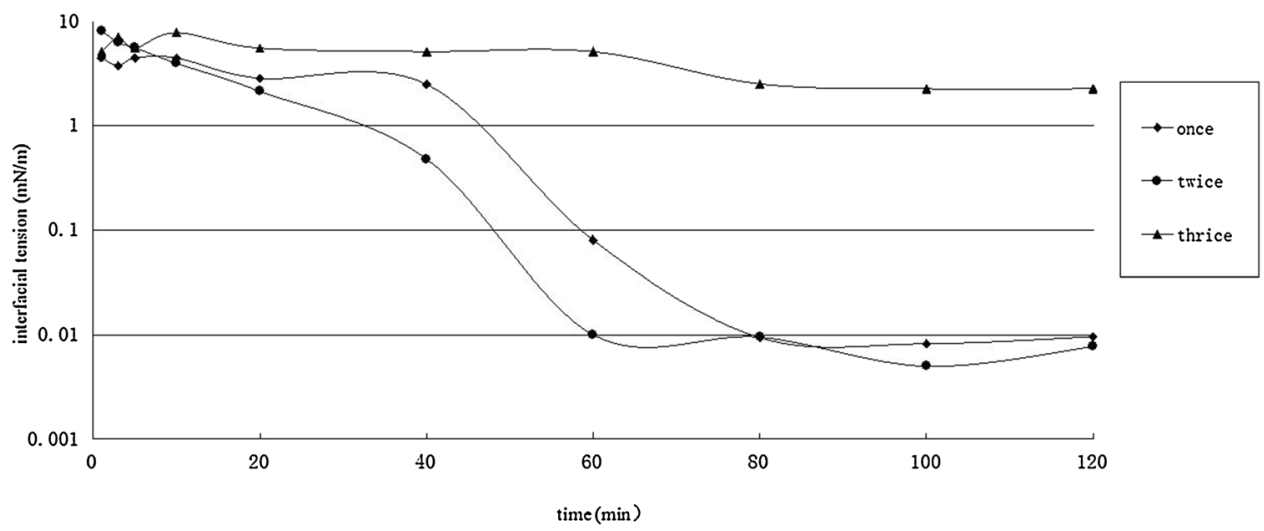

Table 1 Flooding results using sand-packed cores

\begin{tabular}{llllll}
\hline $\begin{array}{l}\text { Surfactant concentration } \\
(\mathrm{m} / \mathrm{m})\end{array}$ & $0.05 \%$ & $0.05 \%$ & $0.10 \%$ & $0.10 \%$ & 0 \\
\hline Polymer concentration (mg/L) & 0 & 1500 & 0 & 1500 & 1500 \\
Core permeability (mD) & 226 & 220 & 195 & 212.8 & 220 \\
Pore volume & 80 & 80 & 79 & 77 & 79 \\
Core porosity (\%) & 32.65 & 32.65 & 32.24 & 31.34 & 32.24 \\
Crude oil saturation (\%) & 81.25 & 80 & 85.54 & 81.82 & 81.01 \\
Ultimate recovery (\%) & 56.9 & 73.44 & 55.5 & 71.7 & 67.5 \\
Additional oil recovery (\%) & 6.2 & 22.5 & 4.24 & 21.6 & 12.88 \\
\hline
\end{tabular}

\section{Core flood experiments}

The core flood results are given in Table 1.

It could be seen from Table 1 , in the absence of polymer, at a surfactant concentration of 0.05 and $0.10 \%$, that 6.2 and $4.24 \%$ of additional oil were recovered, respectively. While in the presence of $1500 \mathrm{mg} / \mathrm{L}$ of polymer, under the same operational condition, the oil recovery was 22.5 and $21.6 \%$, respectively. However, when $1500 \mathrm{mg} / \mathrm{L}$ of polymer was exclusively used, only $12.88 \%$ oil recovery was reached. It is clear that the synergistic effects occurred between the surfactant and polymer. Besides, the oil recovery at $0.05 \%$ surfactant is higher than that of $0.10 \%$ no matter whether polymer existed or not. The reason might be that the equilibrium interfacial tension is relatively lower when $0.05 \%$ of surfactant was used.

\section{Conclusions}

Erucamidopropyl dimethyl amine oxide was prepared by using erucamidopropyl dimethyl amine and hydrogen peroxide. The structure of the synthesized surfactant was confirmed by IR and ESI-MS spectra. And its interfacial tension was studied in the absence or presence of polymer. It was found that in the absence of polymer, the transient interfacial tension could be lowered to ultralow levels. While in the presence of $1500 \mathrm{mg} / \mathrm{L}$, at the concentration of $0.05 \%$ surfactant, the equilibrium interfacial tension could be reached. The absorption experiments showed that the surfactant-polymer system could withstand twice absorption.

Core flood experiment indicated that the oil recovery with $1500 \mathrm{mg} / \mathrm{L}$ of polymer and $0.05 \%$ of surfactant was $22.5 \%$, while with $1500 \mathrm{mg} / \mathrm{L}$ of polymer and $0.10 \%$ of surfactant, only $21.6 \%$ oil recovery was achieved, which might prove the ultralow equilibrium interfacial tension is more effective in oil recovery than the transient one.

Acknowledgements This project was funded by key technical research and application program of increasing and stable 8 million tons of oil production in Huabei oil field (No. 2014E-35-07).

Open Access This article is distributed under the terms of the Creative Commons Attribution 4.0 International License (http:// creativecommons.org/licenses/by/4.0/), which permits unrestricted use, distribution, and reproduction in any medium, provided you give appropriate credit to the original author(s) and the source, provide a link to the Creative Commons license, and indicate if changes were made.

\section{References}

Carmona I, Schechter RS, Wade WH (1985) Ethoxylated oleyl sulfonates as model compounds for enhanced oil recovery. SPE J 25:351-357

Chen YM, Wang HH, Yu JY (2001) Research advance of dynamic interfacial tension behavior in chemical flooding. ACTA Pet Sin 22:97-103

Chu ZL, Feng YJ (2013) Vegetable-derived long-chain surfactants synthesized via a green route. ACS Sustain Chem Eng 1:75-79

Cui ZG, Wu L, Sun MM, Jiang JZ, Wang F (2011) Synthesis of dodecyl lauroyl benzene sulfonate and its application in enhanced oil recovery. Tenside Surf Deterg 48:408-414

Cui ZG, Du XR, Pei XM, Jiang JZ, Wang F (2012) Synthesis of didodecylmethylcarboxyl betaine and its application in surfactant-polymer flooding. J Surfactants Deterg 15:685-694

Kong Y (2009) Study on novel surfactant for enhanced oil recovery. Jiangnan University, Wuxi

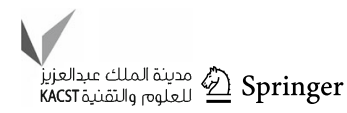


Li LL (2011) Rheological properties and reaction kinetics of amidoamine oxide surfactant-based acids with calcite. Texas A\&M University, College Station

Li HB, Chen ZH (2006) Characteristics of interfacial tension and oil displacement efficiency with alkaline-surfactant-polymer flooding technology. ACTA Pet Sin 27:96-98

Li Y, Duan YZh, Zhang K (2010) Effect of alkanolamide on interfacial tension and loss of petroleum sulfonates for enhanced oil recovery. J Dispers Sci and Technol 31:722-726

Li N, Zhang GC, Ge JJ, Zhang L, Liu XL (2012) Ultra-low interfacial tension between heavy oil and betaine-type amphoteric surfactants. J Dispers Sci Technol 33:258-264

Lu YH (1996) Amine oxide. Chin Surf Deterg Cosmet 6:23-27

Olsen DK (1989) Use of amine oxide surfactants for chemical flooding. Topical Report

Qiao WH, Li J, Zhu YY, Cai HY (2012) Interfacial tension behavior of double long-chain 1, 3, 5-triazine surfactants for enhanced oil recovery. Fuel 96:220-225

Samanta A, Ojha K, Sarkar A, Mandal A (2011a) Surfactant and surfactant-polymer flooding for enhanced oil recovery. Adv Petro Explor De 2:13-18

Samanta A, Ojha K, Mandal A (2011b) The characterization of natural surfactant and polymer and their use in enhanced recovery of oil. Pet Sci Technol 29:765-777
Sanz CA, Pope GA (1995) Alcohol-free chemical flooding: from surfactant screening to coreflood design. In: SPE Proceedings of the SPE international symposium on oilfield chemistry, San Antonio

Shi CX, Liao GZ, Liu WD (2014) Synthesis of internal olefin sulfonate and its application in oil recovery. Arab J Sci Eng 39:37-41

Wang DM, Butler R, Liu H, Ahmed S (2011) Surfactant formulation study for baken shale imbibition. In: SPE annual technical conference and exhibition, Denver

Witthayapanyanon A, Acosta EJ (2006) Formulation of ultralow interfacial tension systems using extended surfactants. J Surfactants Deterg 9:331-339

Zhao ZK, Ba Y, Li ZS, Qiao WH, Cheng LB (2006) Synthesis and interfacial behavior of decyl methylnaphthalene sulfonate. Pet Sci Technol 24:595-606

Zhu YW (2007) A laboratory study of enhancing oil recovery with petroleum sulfonant system after polymer flooding. Petro Explor De 34:212-215

Zhu HJ, Yang HP (1994) The effect of dynamic interfacial tension on displacement efficiency in chemical flooding. Pet Explor Dev 21:74-80 